\title{
PREDICTION OF THERMAL STRATIFICATION OF THE KOTMALE RESERVOIR USING A HYDRODYNAMIC MODEL
}

\author{
K.G.A.M.C.S. ABEYSINGHE, ${ }^{1}$ K.D.W. NANDALAL ${ }^{2 *}$ and S. PIYASIRI ${ }^{1}$ \\ ${ }^{1}$ Department of Zoology, University of Sri Jayewardenepura, Nugegoda. \\ ${ }^{2}$ Department of Civil Engineering, University of Peradeniya, Peradeniya.
}

(Received: 17 November 2003 ; accepted: 27 October 2004)

\begin{abstract}
Strong thermal stratification in a reservoir may result in oxygen depletion along the vertical profile downwards leading to its eutrophication. The paper is an investigation of thermal stratification behaviour of the Kotmale reservoir, which experienced several water quality linked problems in recent times. A one-dimensional reservoir hydrodynamics model is calibrated and validated for the Kotmale reservoir. The calibration and validation are strengthened by calculating several goodness-of-fit statistics. The study further shows the possibility to change the strong thermal stratification of the Kotmale reservoir by manipulating the releases from it. The model that ensures a reasonable prediction of thermal stratification enables taking precautionary measures to avoid adverse reservoir water quality conditions.
\end{abstract}

Keywords: hydrodynamic modeling, reservoir, thermal stratification.

\section{INTRODUCTION}

Reservoirs are built for storing water to increase availability by preventing waste during the periods of high runoff. As these storage impoundments become many and were called on to serve more uses and users, the quality of the water stored in and released from them have come under strict scrutiny to determine its suitability for various purposes. Therefore, the ability to predict the quality of water in reservoirs became important in the management of water resources development works.

When a flowing river is dammed and becomes an impoundment, two major changes occur, which have a marked effect in water quality. Firstly, creating an impoundment greatly increases the time required for water to travel the distance from the headwaters to the discharge at the dam. Secondly, thermal or density and therefore, chemical stratification may take place. Both increased detention time and thermal stratification frequently cause adverse water quality conditions in reservoirs.
The desire to manage the quality of water stored in reservoirs led to the development of numerical models for the simulation of internal dynamics of them. Lakes or reservoirs that do not show significant thermal stratification during the yearly cycle could be modeled assuming that complete mixing occurs throughout its volume during the whole year. ${ }^{11,12}$ However, for reservoirs in which the foregoing condition does not apply, complex models have to be developed to predict thermal gradients, density stratification and the impact that various operating rules may have on these and other physical, chemical and biological quality characteristics of the impoundment water. Much of the development in modeling reservoir dynamics has been done by assuming onedimensionality, where vertical motion is inhibited and transverse and longitudinal variations are quickly evened out. Even with this simplification, it is difficult to model the interactions of a number of complex processes occurring in a reservoir. Over the last several decades diverse models of varying complexity and success have been produced. . $3,4,6,7,10$ There has also been to a less extent some development of two- and threedimensional stratification models..$^{5,8,13}$ However, the increasing complexity and computational requirements have severely limited their development.

Although three-dimensional models describe the water quality and ecology of reservoirs better, one-dimensional models remain attractive, appropriate and convincing for understanding the physical processes occurring in reservoirs. ${ }^{5,8,13}$

Dynamic Reservoir Simulation Model $^{7}$ (DYRESM) is a one-dimensional numerical model that can simulate thermal behavior and water quality distribution in a reservoir and predict the distribution of temperature (and therefore,

* Corresponding author 
density) in reservoirs in response to meteorological forcing, inflow and outflow. The model provides a means of predicting seasonal and inter-annual variability of lakes and reservoirs as well as sensitivity testing to long-term changes in environmental factors or watershed properties.

The Kotmale reservoir, the uppermost reservoir in the comprehensive Mahaweli Development Scheme faced several water quality related problems in the recent past. The ability to predict its temperature distribution, which is closely related to its water quality, would enable precautionary measures to prevent expected poor quality conditions. This paper presents the calibration and validation of DYRESM for the Kotmale reservoir to predict its thermal stratification behavior. Further, the possibility to reduce thermal stratification by manipulating the discharge from the reservoir was also studied.

The paper first presents a brief description of the Kotmale reservoir and its catchment, followed by the descriptions of DYRESM and the statistical methods used in the study. Analysis carried out including calibration and verification of the model for the Kotmale reservoir, a statistical analysis, a study on the impact of releases on reservoir thermal stratification are provided next. Finally the conclusions are given.

\section{METHODS \& MATERIALS}

Site Description: The Kotmale reservoir (shown in Figure 1) has been constructed in the upland of Sri Lanka under the Mahaweli Development Scheme mainly for hydroelectric power generation. It is the uppermost reservoir in the reservoir network constructed under that scheme. The general climate of the area around the reservoir is determined by the southwest monsoon from May to September and by the northeast monsoon from November to March. The reservoir receives water from its catchment of approximately $563 \mathrm{~km}^{2}$ via three main tributaries Pundalu Oya, Puna Oya and Kotmale Oya. These tributaries, which run through the dense tea estates, bring nutrient rich surface runoff into the reservoir.

The climatological data collected at a recording station located close to the dam was used to describe the climatic conditions around the reservoir area. Table 1 presents monthly averages of data observed over the period from 1990 to 1999. As it shows, the lowest temperatures occured from January to February and highest temperatures from February to April. Rainfall varied considerably during the year. Seasonal variation in wind speed (measured at $2 \mathrm{~m}$ above ground surface) was small. The mean monthly wind speed was highest in June and lowest in the period from October to December. Monthly variation of evaporation follows the mean temperature and total radiation variations. The average annual evaporation around the Kotmale reservoir was $1442 \mathrm{~mm}$.

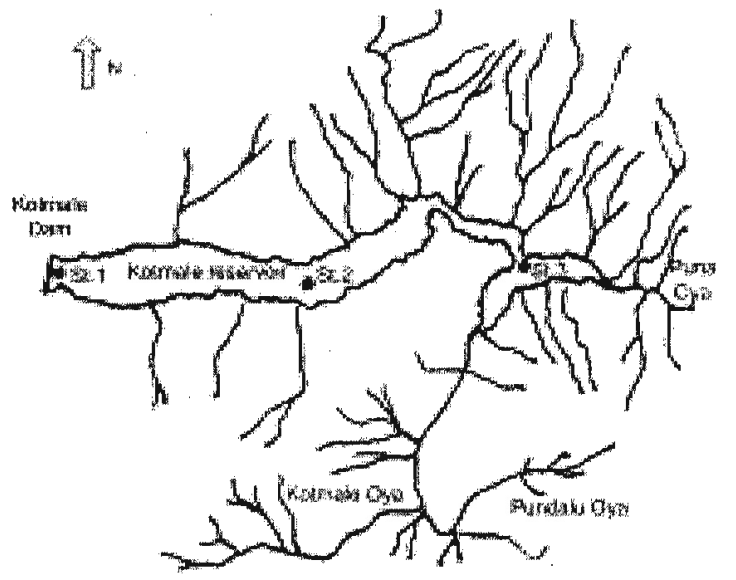

Figure 1: Sampling stations and major inflowing rivers of the Kotmale reservoir

The Kotmale reservoir faced several water quality related problems in the recent past. During a severe drought in 1991, the reservoir water-level dropped and a thick bloom of Microcystis aeruginosa was observed in the upstream region. This shifted towards the dam due to wind action covering the whole surface of the reservoir. ${ }^{16}$ Based on a water quality assessment carried out using water quality data in the Kotmale reservoir from March 1987 to February 1988, Piyasiri ${ }^{15}$ concluded that the Kotmale reservoir thermally stratifies and is subjected to oxygen depletion along the vertical profile indicating sensitivity to eutrophication.

\section{Hydrodynamic Model: DYRESM}

The assumption of one-dimensionality in DYRESM is based on the density stratification usually found in lakes and reservoirs, which inhibits vertical motions while lateral and longitudinal variation in density are quickly 
relaxed by horizontal convection, occurring on time scales shorter than vertical advection. The model has been developed with emphasis on parameterization of the physical processes rather than numerical solution of the appropriate differential equations.

DYRESM uses a Lagrangian Layer Scheme in which the reservoir is represented by a series of horizontal layers of uniform property but of variable thickness. As inflows and outflows enter or leave the reservoir, the affected layers expand or contract and those above move up or down to accommodate the volume change. The vertical movement of layers is accompanied by a thickness change as the layer surface areas change with vertical position in accordance with the reservoir bathymetry. Mixing is modeled by amalgamation of adjacent layers, and the layer thicknesses are dynamically set internally by the model to ensure that for each process, an adequate resolution is obtained.

Even with the assumption of onedimensionality, the vertical density structure is the result of a complex interaction of a number of processes active in lakes and reservoirs. These individual processes are parameterized in DYRESM. The development of DYRESM is described in detail in the literature, ${ }^{6,7,14,21}$ including descriptions of the process parameterizations. The processes included in the model are surface heat, mass and momentum exchanges, surface mixed layer deepening model, inflow, outflow, mixing in the hypolimnion and bubble plume destratification.

DYRESM has been validated on several lakes and reservoirs; Lake Burragorang (large and deep) during a drought and Prospect reservoir (small and shallow) both located near Sydney, Australia, over a period of 8 years, are two applications ${ }^{18}$ of it. Its major development and validation was in Wellington reservoir, an irrigation supply reservoir situated in the southwest of Western Australia. A quantitative measure of the performance of the model is given in Patterson et al..$^{14}$

The data required for the DYRESM model are daily values of air temperature, relative humidity, wind velocity, solar radiation, rainfall, evaporation, inflow quantity, and outflow quantity. 
Table 2: General and morphometric characteristics and Physico-chemical data of the Kotmale reservoir

(a) General Characteristics

\section{Latitude \\ Longitude}

Full supply level (MSL)

Extreme flood level (MSL)

Minimum operating level

Storage capacity

(at Full supply level)

(at Minimum operating level)

Catchment area

Major inflowing rivers

Minor inflowing rivers

Kuda Oya, Gerande Ella Helaboda Ella-1,

Helaboda Ella-1l, Ramboda Ella-1,Ramboda

Ella-ll

Outflowing river

Mahaweli river

(b) Morphometric Characteristics

Surface area
Maximum length
Maximum breadth
Maximum depth
Mean depth
Shore line (SL)
Mean river flow

$6.5 \mathrm{~km}^{2}$

$6.8 \mathrm{~km}$

$1.41 \mathrm{~km}$

$90 \mathrm{~m}$

$26.8 \mathrm{~m}$

$45 \mathrm{~km}$

$96 \mathrm{~m}^{3} / \mathrm{sec}$
$172.9 \times 10^{6} \mathrm{~m}^{3}$

$22.2 \times 10^{6} \mathrm{~m}^{3}$

$\mathrm{km}^{2}$

Kotmale Oya, Pundalu Oya, Puna Oya

akaduru Oya, Kahahena Ella, Raja Ella, (c) Physio-chemical data

$\begin{array}{ll}\text { Surface temperature } & 21.6-28.6^{\circ} \mathrm{C} \\ \text { Hypolimnion temperature } & 22.73^{\circ} \mathrm{C} \\ \text { Conductivity(surface) } & 19-199.9 \mathrm{mS} \mathrm{cm}{ }^{-1} \\ \text { pH(surface) } & 6.05-9.2 \\ \text { Transparency(secchi disk) } & 0.8-3.47 \mathrm{~m} \\ \text { Temperature (inflowing rivers) } & 18.4-21.8^{\circ} \mathrm{C} \\ & \text { (Right bank) } \\ & 19.4-23.2^{\circ} \mathrm{C} \\ & \text { (Left bank) }\end{array}$

Statistical Analysis (Fit statistics): The ability of the model to simulate observed conditions was tested with two goodness-of-fit statistics: the root mean squared error (RMSE), and the mean of the relative absolute error (MRAE).

The RMSE is defined as the square root of the mean of the squared difference between observed and simulated values.

$R M S E=\sqrt{\frac{1}{n} \sum_{i=1}^{n}\left(x_{s, i}-x_{o, i}\right)^{2}}$

Where, $x_{s, i}$ and $x_{o, i}$ are the simulated and observed $i^{\text {th }}$ values and, $n$ is the sample size. In this analysis, we use the root mean square error as the measure of error between computed and observed temperatures.
As such, the RMSE is similar to a standard deviation of the error, ${ }^{19}$ roughly twothirds of the errors are expected to fall within \pm 1 . R'MSE values have the units of the quantity of interest, and lower values indicate a better fit. For the statistic to be relevant, however, one must know the range of the fitted data to determine whether an RMSE indicates an excellent or poor fit.

The MRAE is the mean of the absolute value of relative errors. Lam et al.$^{9}$ expressed this statistic as the following, Variables are as defined before.

There are limitations for using the above equation, specifically, there is poor behaviour of MRAE at low values of $x_{o . i}$ and the variability of the data is not adequately recognized. The MRAE is also constrained if $x_{o . i}$ is much greater than $x_{s, i}$. 
However, an advantage of the MRAE is that this statistic is a readily understood comparison and can provide a gross measure of model adequacy and can be useful in comparing models.

$M R A E=\frac{1}{n} \sum_{i=1}^{n} \frac{\left|x_{o, i}-x_{s, i}\right|}{x_{o, i}}$

Data Collection: The study area of the reservoir and its tributaries are depicted in Figure 1. Water samples have been collected once a month from three stations St.1, St.2, and St.3, vertically from top to bottom at $10 \mathrm{~m}$ intervals. St. 1 located closer to the dam is the deepest region in the reservoir. St.3 is close to the major inflowing rivers (Kotmale Oya, Pundalu Oya, Puna Oya), while St.2 is in the middle of the reservoir. Physical, chemical and biological water quality parameters measured in these water samples are temperature, dissolved oxygen concentration, electrical conductivity, $\mathrm{pH}$, chloride, total alkalinity, suspended solids, nitrogen, ammonia, nitrate, nitrite, biological oxygen demand, fluoride, heavy metals, chlorophyll and phytoplankton. This study uses the data collected at the station St.1. These water quality data have been collected through a limnology project at Mahaweli reservoirs by the
Department of Zoology, University of Sri Jayawardenapura, Nugegoda. ${ }^{17}$

The daily values of air temperature, relative humidity, wind velocity, rainfall, evaporation, reservoir inflow quantity, inflow quality and outflow quantity, which are required for the model were collected from the Headworks Administration, Operation and Maintenance unit of the Mahaweli Authority of Sri Lanka. Actual duration of sunshine hours, which were used to estimate solar radiation, were collected from Natural Resource Management Centre at Peradeniya.

\section{RESULTS AND DISCUSSION}

\section{Data for the model}

The DYRESM model for the Kotmale reservoir was calibrated using the data collected during 1995. Except short wave radiation and daily inflow temperatures, all the other data required for the model were available for that year. However, records of daily sunshine duration were available for the area. Using that, the short wave radiation were estimated based on the Angstrom formula ${ }^{1,20}$ which relates solar radiation to extraterrestrial radiation and relative sunshine duration.

Table 3: Parameters of the DYRESM model for the Kotmale reservoir

\begin{tabular}{|c|c|}
\hline Parameter & Value for Kotmale reservoir \\
\hline Neutral $10 \mathrm{~m}$ aerodynamic drag coefficient & $1.3 \times 10^{-3}$ \\
\hline Mean albedo of water & 0.3 \\
\hline Emissivity of a water surface & 0.97 \\
\hline Light extinction coefficient & 0.3 \\
\hline Critical wind speed at $10 \mathrm{~m}$ height $\left[\mathrm{m} \mathrm{s}^{-1}\right]$ & 4.00 \\
\hline Time of day for output (in seconds from midnight) & 43200 \\
\hline Entrainment coefficient constant & $2.0 \times 10^{-3}$ \\
\hline Bubbler entrainment coefficient & 0.006 \\
\hline Buoyant plume entrainment coefficient & 0.083 \\
\hline Shear production efficiency & 0.06 \\
\hline Potential energy mixing efficiency & 0.20 \\
\hline Wind stirring efficiency & 0.06 \\
\hline Effective surface area coefficient & $1.0 \mathrm{E}+07$ \\
\hline Vertical mixing coefficient & 200 \\
\hline
\end{tabular}


Maximum possible duration of sunshine hours and extraterrestrial radiation for different latitudes listed in FAO publication No.56 were adopted in the study. ${ }^{1}$ The constants in the Angstrom formula were obtained from the modified Fre're curves for Sri Lanka by Samuel. ${ }^{20}$ Daily inflow temperatures were estimated as the average of the air temperatures during the 4 days preceding the date of the inflow entering the reservoir, as suggested by the model developers.

Initial reseirvoir water level, temperature and salinity are required to start a simulation. Initial water level was set to the observed water level of the reservoir on the first day of the simulation period. Observed water temperature and salinity profiles at St.1 on that day were available for the initial condition of the reservoir.

\section{Model parameters}

The model parameters are given in Table 3. However, many of them cannot be measured directly and were obtained by a trial and error procedure of comparing the temperature obtained from the model DYRESM simulations with observations. Most of the hydrodynamic and thermal processes in a reservoir are simulated in the DYRESM model. The mean albedo of water, emissivity of water surface and light extinction coefficient were found to be very sensitive parameters, while the other parameters were relatively insensitive.

\section{Reservoir mass balance}

The model gives the reservoir water level during the simulation period. Comparison with the observed reservoir water levels during the simulation period from $19^{\text {th }}$ January to $31^{\text {st }}$ December, 1995 shows good agreement as evident from Figure 2. RMSE between measured and simulated water levels was $0.133 \mathrm{~m}$. The difference between the measured and simulated water levels ranged from $-0.56 \mathrm{~m}$ to $0.53 \mathrm{~m}$ with a mean difference of $0.076 \mathrm{~m}$.

\section{Temperature variation}

Near-surface and near-bottom $(50 \mathrm{~m}$ below water surface) water temperatures obtained from the model DYRESM at the calibration were compared with the observed values in Figure 3. Simulated near-surface and near-bottom water temperatures were generally within $1^{\circ} \mathrm{C}$ of the corresponding observed values indicating a good fit. Differences between simulated and observed values ranged from $-1.3^{\circ} \mathrm{C}$ to $1.2^{\circ} \mathrm{C}$ and the average difference was $0.5^{\circ} \mathrm{C}$.

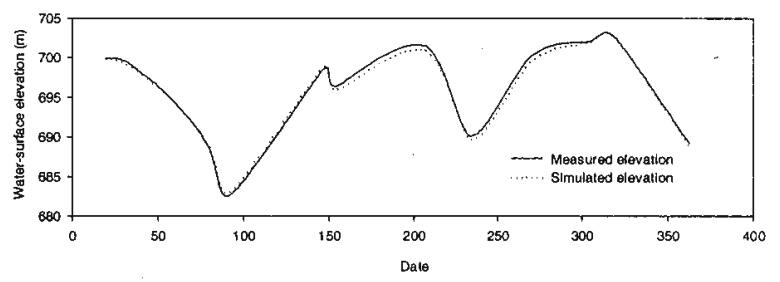

Figure 2: Observed and simulated water levels of the Kotmale reservoir during calibration

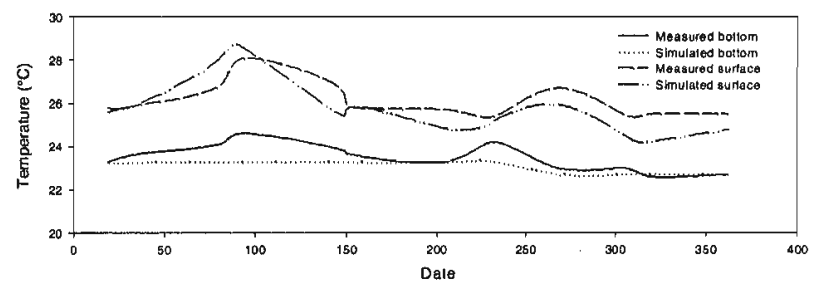

Figure 3: Observed and simulated nearsurface and near-bottom water temperatures of the Kotmale reservoir at St.1 during calibration

The DYRESM simulated water temperatures (84 observations) for January through December 1995 were compared with corresponding observed values for St.1 during the calibration stage to decide the model parameter values. Figure 4 presents the comparison, which indicates a very good fit. Measured water temperatures ranged from $22.2^{\circ} \mathrm{C}$ to $28.1^{\circ} \mathrm{C}$. Differences between measured and simulated temperatures ranged from $-1.2^{\circ} \mathrm{C}$ to $1.5^{\circ} \mathrm{C}$ with a RMSE of $0.47^{\circ} \mathrm{C}$. The MARE between measured and simulated water temperatures was $2.18 \%$ of the observed values. Eighty eight percent of the simulated temperatures were within $1^{\circ} \mathrm{C}$ of the measured temperature.

The monthly goodness of-fit statistics between observed and simulated temperatures for the calibration period are given in Table 4 . These two fit-statistics have been used to investigate the suitability of models in simulating real situations in many areas. Rounds and Wood ${ }^{19}$ examined the fitness of a water quality model developed for a river based on them. 

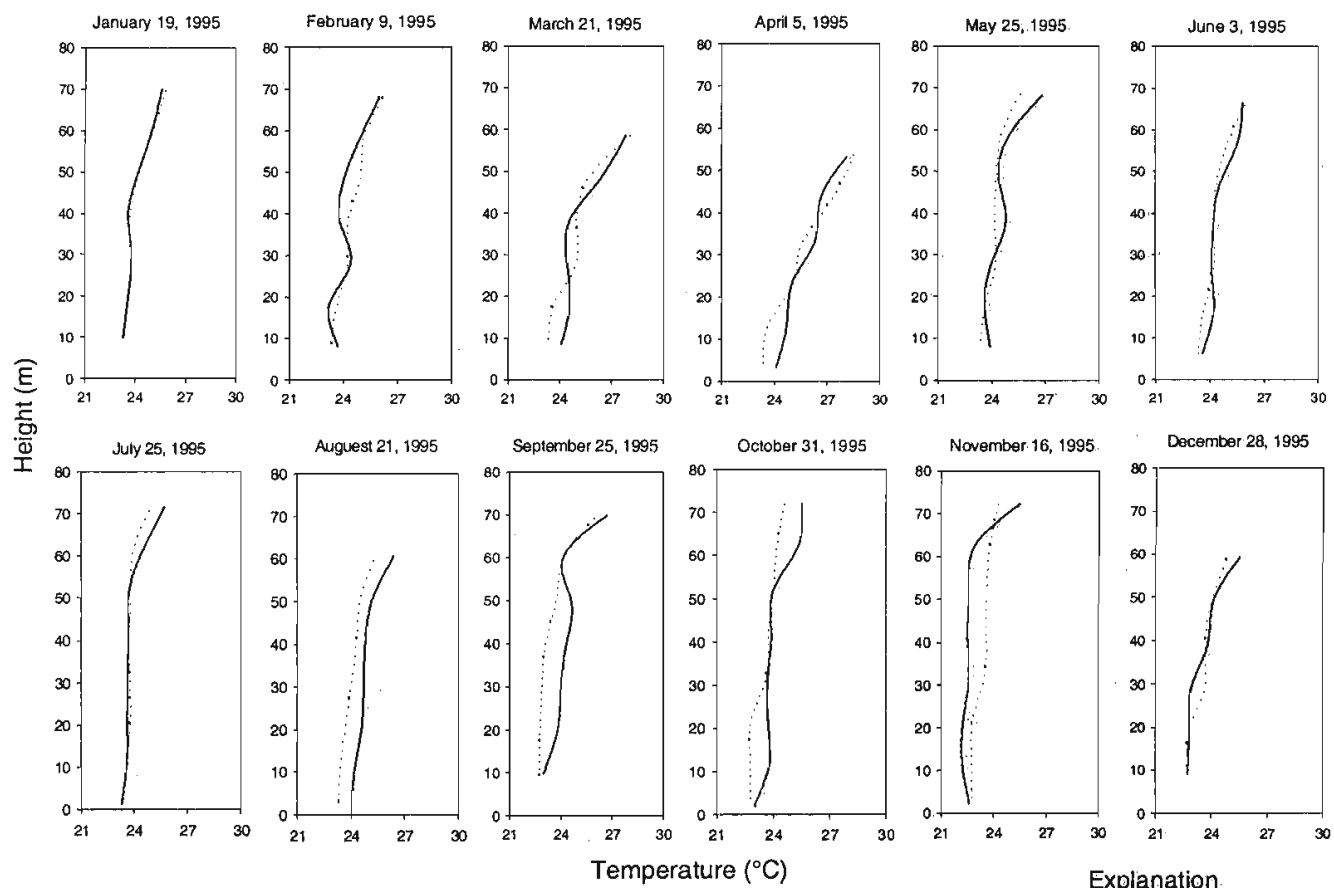

Explanation

- Measured

Simulated

\section{Figure 4: Observed and simulated vertical profiles of water temperature of the Kotmale reservoir at St.1 from January 19 to December 28, 1995}

Table 4: Goodness-of-fit statistics between observed and simulated temperatures during the calibration period

\begin{tabular}{lcccccccccccccc}
\hline & \multicolumn{11}{c}{ Calibration year 1995} \\
\cline { 2 - 13 } & Jan & Feb & Mar & Apr & May & Jun & Jul & Aug & Sep & Oct & Nov & Dec & Mean \\
& 19 & 9 & 21 & 5 & 25 & 3 & 25 & 21 & 25 & 31 & 16 & 28 & \\
\hline $\operatorname{RMSE}\left( \pm^{\circ} \mathrm{C}\right)$ & 0.008 & 0.195 & 0.667 & 0.854 & 0.372 & 0.347 & 0.145 & 0.710 & 0.782 & 0.742 & 0.698 & 0.170 & 0.474 \\
& & & & & & & & & & & & & \\
$\operatorname{MRAE}(\%)$ & 0.226 & 1.558 & 3.000 & 3.022 & 1.868 & 1.615 & 0.913 & 3.286 & 3.169 & 2.874 & 3.304 & 1.273 & 2.176 \\
\hline
\end{tabular}

In summary; $0.008 \leq \operatorname{RMSE}\left( \pm^{\circ} \mathrm{C}\right) \leq 0.854, \quad 0.226 \leq \operatorname{MRAE}(\%) \leq 3.304$

The monthly goodness of-fit statistics between observed and simulated temperatures for the calibration period are given in Table 4 . These two fit-statistics have been used to investigate the suitability of models in simulating real situations in many areas. Rounds and Wood ${ }^{19}$ examined the fitness of a water quality model developed for a river based on them.

\section{Sensitivity analysis}

Sensitivity analysis is the determination of the effects of small changes in calibrated model parameters on model results. Many simulations were conducted as a component of the model calibration. Results from these simulations form the basis for the sensitivity analysis.

Of the hydraulic and thermal parameters in Table 3 , simulated temperatures were most sensitive to changes in the emissivity of water surface (EWS), mean albedo of water (MAW) and light extinction coefficient (LEC). Figure 5 presents the results of this analysis based on temperature profiles on the days 21 March, 3 June, 25 September and 28 December in the year 1995. The epilimnetic temperature is very sensitive to EWS and MAW and less sensitive to LEC, while the hypolimnetic 
(a) 21-March-1995
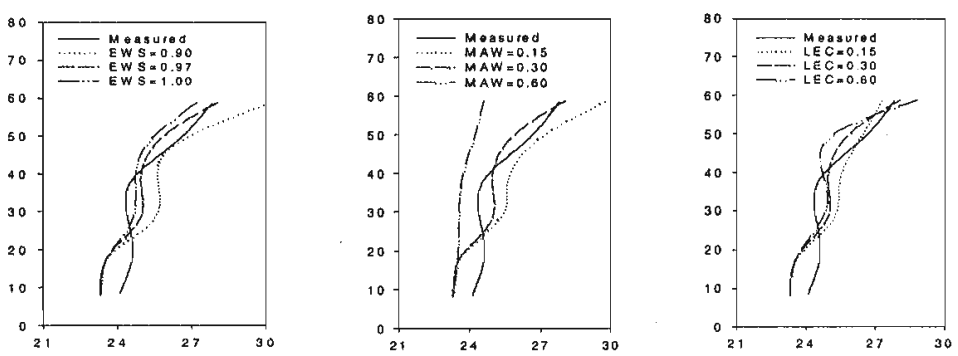

(b) 3-June-1995
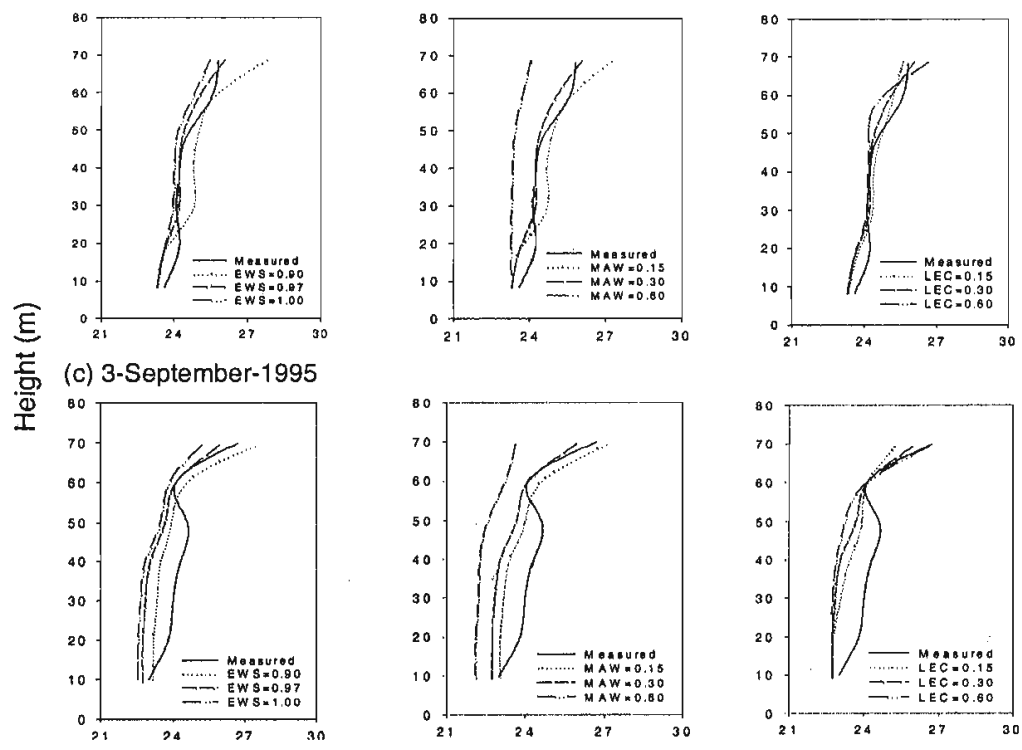

(d) 28-December-1995
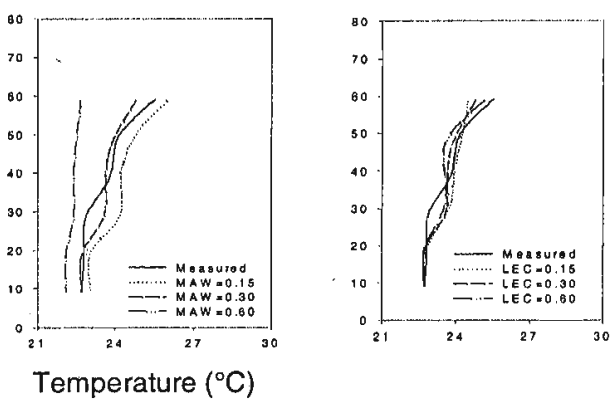

Figure 5: Sensitivity analysis of DYRESM parameters, mean albedo of water, emissivity of a water surface and light extinction coefficient based on the temperature profiles of $21 / 3 / 1995,3 / 6 / 1995,25 / 9 / 1995$ and $28 / 12 / 1995$

temperature shows a less sensitivity to these three parameters. Low MAW values seem to be over predicting reservoir vertical mixing. The results on 25 September shows that the model sometimes predicts more mixing compared to the actual behavior.

\section{Model verification}

To verify the accuracy of the parameters of the model calibrated using the data in the year 1995, the reservoir was simulated for the year 1996 and the results were compared with the observed temperatures.

Figure 6 presents the comparison of simulated and observed water temperatures at the near-surface and near-bottom ( $50 \mathrm{~m}$ below water surface) of the Kotmale reservoir. Simulated near-surface and near-bottom water temperatures were generally within $1^{\circ} \mathrm{C}$ of the corresponding observed values. Differences between simulated and measured values ranged from $-1.3^{\circ} \mathrm{C}$ to $1.2^{\circ} \mathrm{C}$ and the average difference was $0.5^{\circ} \mathrm{C}$. 


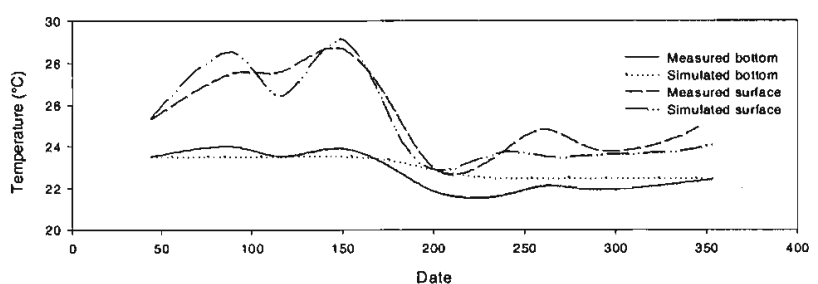

Figure 6: Observed and simulated nearsurface and near-bottom water temperatures of the Kotmale reservoir at $\mathrm{St} .1$ during verification

Figure 7 presents the isotherms of the Kotmale reservoir during the verification period. The isotherms resulting from the DYRESM model shown in Figure 7(b) are very similar to the observed isotherms in Figure 7(a). These figures reveal the fact that the Kotmale reservoir was thermally stratified throughout the year 1996 . During the dry months, February to May, it is very strongly stratified.
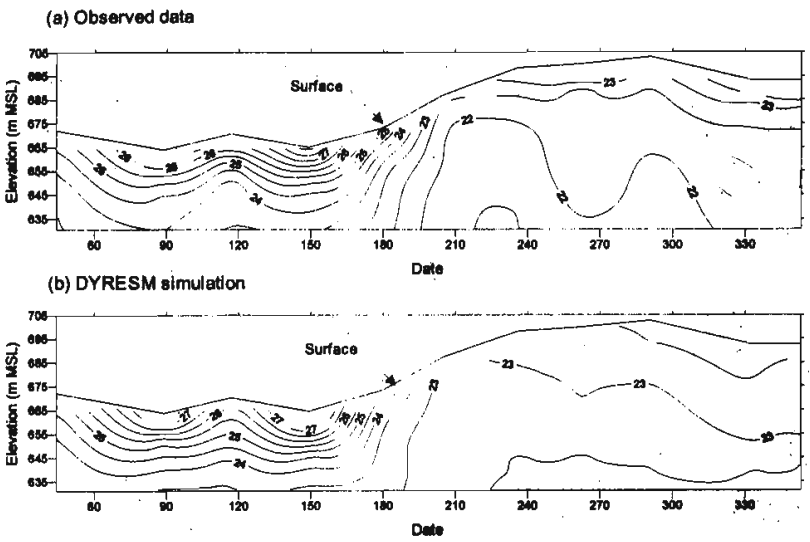

Figure 7: Comparison of isotherms in the Kotmale reservoir - Validation year 1996
Further, Figure 8 presents the comparison of all observed water temperatures (64 observations) for February through December 1996 with corresponding simulated values for St.1. Observed water temperatures in 1996 ranged from $20.5^{\circ} \mathrm{C}$ to $28.1^{\circ} \mathrm{C}$. Differences between measured and simulated temperatures ranged from $-1.8^{\circ} \mathrm{C}$ to $1.6^{\circ} \mathrm{C}$ with a RMSE of $0.65^{\circ} \mathrm{C}$. The MRAE between measured and simulated water temperature was $2.67 \%$ of the observed values, indicating a good calibration of the model. Eighty six percent of the simulated temperatures were within $1^{\circ} \mathrm{C}$ of the measured temperature. Simulated water temperatures during the 1996 verification period, like the 1995 calibration period, provided an excellent simulation of water temperature in the Kotmale reservoir, with most simulated values within plus or minus $1^{\circ} \mathrm{C}$ of the observed value.

For the verification period, fit statistics are as follows. The monthly goodness of-fit statistics between observed and simulated temperatures are given in Table 5.

\section{Impact of releases on thermal stratification}

The Kotmale reservoir is observed to be stratified throughout the year. Stratification can cause adverse water quality conditions in the reservoir. Therefore, the possibility to reduce stratification by the manipulation of withdrawal from the Kotmale reservoir was of interest. Withdrawals from the reservoir were changed during the first three months of the year 1996 to study the change in the stratification that would occur in the reservoir. Initially, the withdrawals during the first three months were increased by $25 \%$ to study the impacts on stratification. Figure 9 shows the thermal stratification in the reservoir throughout

Table 5: Goodness-of-fit statistics between observed and simulated temperatures during the verification period

\begin{tabular}{lccccccccccccc}
\hline & \multicolumn{11}{c}{ verification year 1996} \\
\cline { 2 - 11 } & Feb & Mar & Apr & May & Jun & Jul & Aug & Sep & Oct & Nov & Dec & Mean \\
& 13 & 29 & 26 & 28 & 28 & 23 & 23 & 18 & 17 & 28 & 18 & \\
\hline $\begin{array}{l}\text { RMSE } \\
\left( \pm^{\circ} \mathrm{C}\right)\end{array}$ & 0.019 & 0.742 & 0.697 & 1.363 & 0.236 & 0.883 & 0.683 & 0.644 & 0.917 & 0.496 & 0.488 & 0.652 \\
$\begin{array}{l}\text { MRAE } \\
(\%)\end{array}$ & 0.398 & 2.344 & 2.024 & 3.494 & 1.727 & 4.049 & 3.484 & 3.095 & 3.942 & 2.842 & 1.983 & 2.671 \\
\hline
\end{tabular}



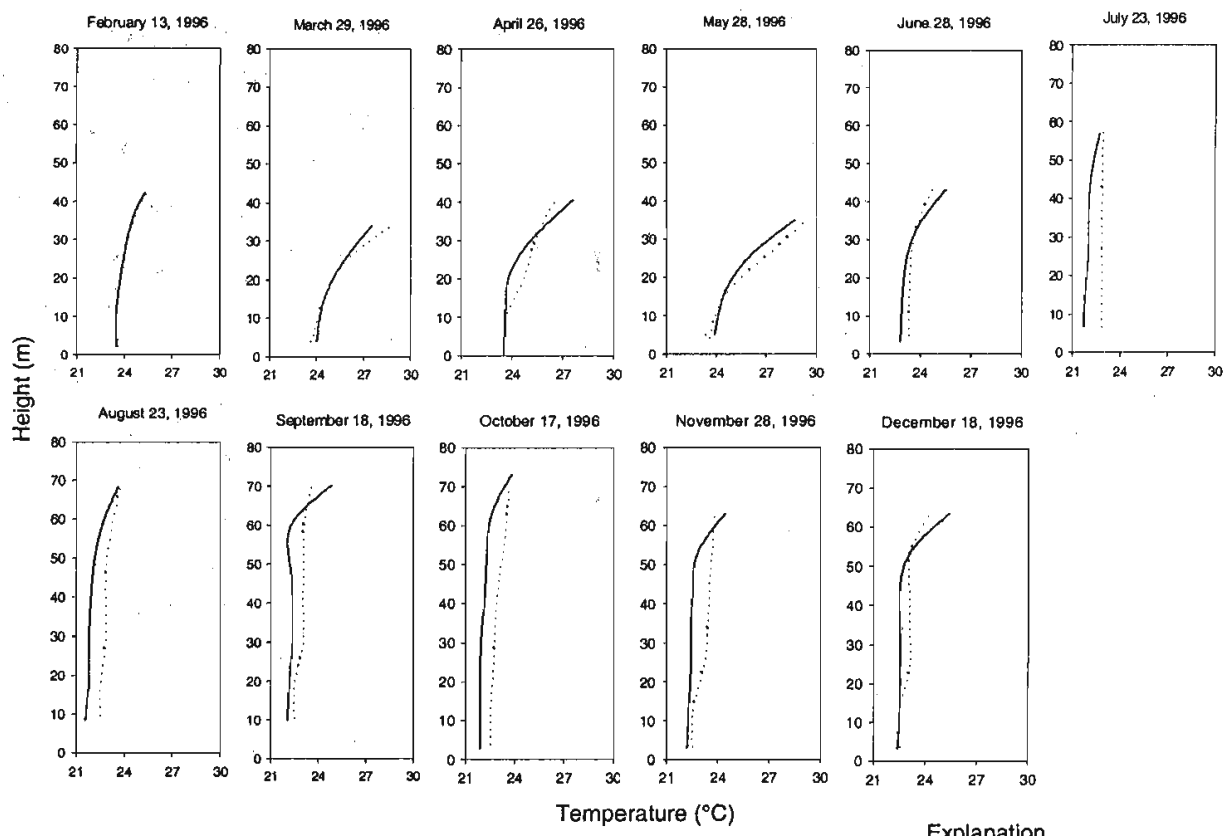

Explanation

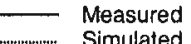

Figure 8: Observed and simulated vertical profiles of water temperature of the Kotmale reservoir at St.1 during verification

the year obtained from the simulation with the model DYRESM.

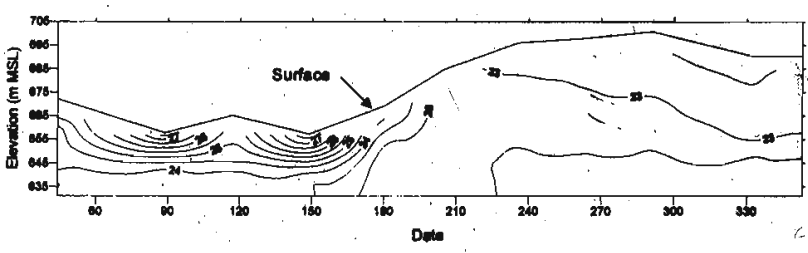

Figure 9: Isotherms in the Kotmale reservoir with increased withdrawals

Its comparison with Figure 7 indicates that the thermal stratification is slightly reduced in the months during which withdrawals have been changed. However, in the second half of the year, the stratification has been reduced considerably.

Subsequently, a change to the reservoir stratification due to a reduced withdrawal from the reservoir was studied. Figure 10 presents thermal isolines when the withdrawals from the reservoir during the first three months were reduced by $25 \%$.

The figure depicts a considerable reduction in the thermal stratification due to a reduction in the withdrawals. Specially, during the second half of the year a sharp reduction starting with a reservoir mixing in June is observed to be occurring in the Kotmale reservoir. These observations indicate the possibility to change the stratification of the reservoir by the manipulation of the withdrawals from the reservoir, which can be used to reduce expected undesirable water quality conditions.

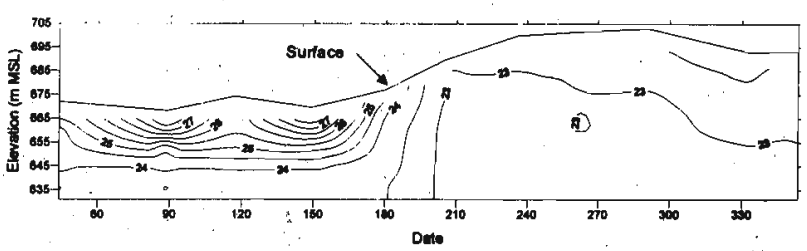

Figure 10: Isotherms in the Kotmale reservoir with decreased withdrawals

\section{CONCLUSIONS}

A one-dimensional hydrodynamic model, DYRESM, was calibrated and verified for the simulation of thermal stratification of the Kotmale reservoir. The model predicted thermal stratification in the reservoir with fair precision. Predictions of the onset of stratification, surface 
temperature, hypolimnetic temperature and mixed-layer depths were all in agreement with the observations. The quantitative and qualitative criteria of model prediction showed that the model could simulate the annual dynamics reasonably well. The Kotmale reservoir was observed to be thermally stratified throughout the year.

The model enables the prediction of thermal stratification in the reservoir body using data that can be collected easily, such as climatological data and reservoir inflow quantity and quality. This could avoid continuous expensive reservoir water quality monitoring programmes.

Since thermal stratification in a reservoir determines the water quality in a reservoir body, the model enables predicting adverse effects with respect to water quality in the reservoir. In such situations, reservoir managers will be able to take precautionary measures by controlling stratification in the reservoir by manipulating withdrawals. The study, based on two different withdrawal patterns, has shown that stratification in the Kotmale reservoir could be altered by manipulating the withdrawal. Thus, the impact of many alternative operational patterns on thermal stratification in the reservoir could be studied with the help of the model in advance to avoid adverse water quality conditions in the reservoir as well as in water supplied from the reservoir.

\section{Acknowledgement}

Financial support provided (RG/2001/E/01) by the National Science Foundation, provision of data by Headworks Administration, Operation and Maintenance unit of the Mahaweli Authority, and Natural Resource Management Centre, Peradeniya and permission to use the DYRESM model by University of Western Australia are gratefully acknowledged.

\section{References}

1. Allen R.G., Pereira L.S., Raes D. \& Smith M. (1998). Crop evapotranspiration Guidelines for computing crop water requirements. FAO Irrigation and drainage paper 56, FAO, Rome.
2. Dake J.M.K. \& Harleman D.F.R. (1969). Thermal stratification in lakes-analytical and laboratory studies. Water Resources Research 5: 484-495.

3. Hostetler S. W. \& Bartlein P.J. (1990). Simulation of lake evaporation with application to lake level variations of Harney-Malheur, Oregon. Water Resources Research 26: 2603-2612.

4. Huber W. C., Harleman D. R. F. \& Ryan P.J. (1972). Temperature prediction in stratified reservoirs. Journal of Hydraulics Division, ASCE 98: 645-665.

5. Hamilton D. P. \& Schladow S.G. (1997). Prediction of water quality in lakes and reservoirs. Part I. Model description. Ecological Modeling 96: 91-110.

6. Imberger J., Patterson J. C., Hebbert B. \& Loh I.C. (1978). Dynamics of reservoir of medium size. Journal of the Hydraulic Division, ASCE 104(HY5):725-743.

7. Imberger J. \& Patterson J.C. (1981). A dynamic reservoir simulation modelDYRESM: 5, In: Transport Models for Inland and Coastal Waters, (Ed. H.B. Fisher) Academic Press Inc., New York, USA, pp.310-361.

8. Joehnk K. D. \& Umlauf L. (2001). Modeling the metalimnetic oxygen minimum in a medium sized alpine lake. Ecological Modeling 136: 67-80.

9. Lam D.C.L., Schertzer W.M. \& Fraser A.S. (1983). Simulation of Lake Erie water quality responses to loading and weather variations, IWD Scientific Series No.134, National Water Research Institute, Canada Centre for Inland Waters, Burlington, 232p.

10. Markofsky M. \& Harleman D.R.F. (1973). Prediction of water quality in stratified reservoirs, Journal of the Hydraulic Division ASCE 99(HY5): 729-745.

11. Nandalal K.D.W. (1995). Reservoir management under consideration of stratification and hydraulic phenomena. PhD Dissertation, Department of Water 
Resources, Wageningen Agricultural University, The Netherlands.

12. O'Connor D.J. \& Mueller J.A. (1970). A water quality model of chloride in Great Lakes, Journal of the Sanitary Engineering Division, ASCE 96(SA4): 955-975.

13. Orlob G. T. (1983). Mathematical modeling of water quality: streams, lakes and reservoirs. In: Series on Applied System Analysis, (Ed. G.T. Orlob). Wiley IIASA, Inter.

14. Patterson J. C., Hambling P. F. \& Imberger J. (1984). Classification and dynamic simulation of the vertical density structure of lakes, Limnological Oceanography 29:845-861.

15. Piyasiri S. (1991). Limnology project at Mahaweli Reservoirs, Some properties of Kotmale, Victoria and Randenigala reservoirs, Vidyodaya Journal of Science 3(1):45-61.

16. Piyasiri S. (1995). Eutrophication and blue green algal bloom problem of Kotmale reservoir in Sri Lanka. Satya Wacana University Press, Salatiga, Indonesia.
17. Piyasiri S. (1996). Limnology project at Mahaweli Reservoirs, Annual Report, Department of Zoology, University of Sri Jayewardenepura.

18. Romero J.R., Dallimore C.P., Antenucci J.P., Hamilton D.P., Imberger J., Horn D.A. \& Deen A. (2002). Application of $1 D$ and $3 D$ Hydrodynamic Models Coupled to an Ecological Model to Two Water Supply Reservoirs. Progress Report 2, pp.307-312. Centre for Water Research, University of Western Australia, Crawley WA 6009, Australia.

19. Rounds S. A. \& Wood T.M. (2001). Modeling water quality in the Tualatin River, Oregon, 1991-1997. Water-Resources Investigations Report 01-4041.

20. Samuel T.D.M.A. (2000). Solar radiation distribution over Sri Lanka, Bulletin No.1, Solar Research Laboratory, University of Peradeniya.

21. Spigel R.H. \& Imberger J. (1980). The classification of mixed-layer dynamics in lakes of small to medium size, Journal of Oceanography 10: 1104-1121. 